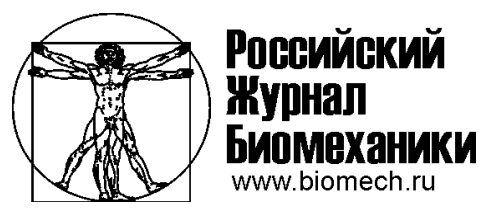

\title{
ПРИМЕНЕНИЕ НАВОДОРОЖЕННЫХ ТИТАНОВЫХ ПОРОШКОВ ДЛЯ ПОЛУЧЕНИЯ ВАКУУМНЫМ СПЕКАНИЕМ ПОРИСТЫХ ПОКРЫТИЙ НА ХИРУРГИЧЕСКИХ ИМПЛАНТАТАХ
}

\author{
В.В. Астанин ${ }^{1}$, Э.3. Каюмова ${ }^{1}$, В.В. Никитин ${ }^{2}$, А.И. Фархетдинов ${ }^{1}$ \\ ${ }^{1}$ Кафедра материаловедения и физики металлов Уфимского государственного авиационного технического \\ университета, Россия, 450000, Республика Башкортостан, Уфра, ул. К. Маркса, 12, e-mail: office@ugatu.su \\ ${ }^{2}$ Кафедра травматологии и ортопедии Башкирского государственного медицинского университета, Россия, \\ 450000, Республика Башкортостан, Уфа, ул. Ленина, 3, e-mail: rectorat@bgmy.ru
}

\begin{abstract}
Аннотация. Успех применения металлических материалов в ортопедии и травматологии во многом зависит от характера взаимодействия имплантата с живой костной тканью организма. На основе литературных данных определено, что шероховатая поверхность медицинских имплантатов оказывает благоприятное влияние на остеоинтеграционные процессы. Наилучшие результаты отмечаются для поверхностей с регламентированной пористостью. Но шероховатость и пористость поверхности отрицательно влияют на усталостную прочность при циклических нагрузках. Исследования разрушенных имплантатов, предоставленных практикующими травматологами-ортопедами, показали, что во всех случаях разрушения носят усталостный характер. Неровности на поверхности имплантатов играют роль концентраторов напряжений и стимулируют образование усталостных трещин. Следовательно, для устранения противоречий между требованиями остеоинтеграции и усталостной прочностью необходимо получить оптимальную структуру поверхности. Методом математического моделирования проведена оценка концентрации напряжений для различных форм шероховатости поверхности и определена структура поверхности титановых имплантатов, наименее предрасположенная к зарождению усталостных трещин. В результате предложен метод получения такой поверхности, заключающийся в вакуумном диффузионном спекании порошков с гладкой поверхностью основания имплантата. Подробно рассмотрено влияние температуры и времени спекания на получение пористой поверхности. Более того, экспериментально получены данные о положительном влиянии водорода, содержащегося в порошке, на процесс спекания. Исходя из литературных данных о прочности соединения имплантата с костной тканью, в работе проведен расчет необходимой относительной площади, занятой перешейками между частицами порошка и основанием имплантата. Выявлены температурно-временные режимы, способствующие формированию регламентированной структуры поверхности.
\end{abstract}

Ключевые слова: имплантат, усталость материала, метод конечных элементов, шероховатость поверхности, диффузионное спекание.

\section{ВВЕДЕНИЕ}

Современная ортопедия и хирургия предъявляют высокие требования к применяемым в протезировании металлическим материалам: экстремальной химической инертности, биологической совместимости с живыми тканями, высокого

(С Астанин В.В., Каюмова Э.З., Никитин В.В., Фархетдинов А.И., 2015

Астанин Владимир Васильевич, д.ф.-м.н., профессор кафедры материаловедения и физики металлов, Уфа Каюмова Эльвира Зинфировна, аспирант кафедры материаловедения и физики металлов, Уфа Никитин Валентин Викторович, д.м.н., профессор кафедры травматологии и ортопедии, Уфа Фархетдинов Айрат Илдарович, студент кафедры материаловедения и физики металлов, Уфа 
уровня механических свойств и надежности. Только такой подход позволит избегать различного рода послеоперационных осложнений и повторных операций в случае абсцессов, коррозии или разрушения имплантатов [5]. Особенно высокие требования предъявляются к имплантатам, предназначенным для остеоинтеграции, когда имплантат устанавливается на длительный срок или пожизненно.

В современной медицине в качестве материалов для изготовления имплантатов широко используются титан и его сплавы благодаря высокой коррозионной стойкости, малому удельному весу, высокой прочности и низкому модулю упругости [2, 6, 7], приближенному к свойствам кости, что обеспечивает механическую совместимость.

С целью повышения потребительских свойств медицинских материалов, в том числе имплантатов для травматологии и ортопедии, применяют различные виды обработки поверхности, в частности, используется метод порошковой металлургии для нанесения пористых покрытий [4]. Пористая структура поверхности позволяет увеличить площадь взаимодействия имплантата с костной тканью и повышает прочность соединения. На процесс остеоинтеграции, в случае пористой поверхности имплантата, большое влияние оказывают форма и размеры пор. В работе [4] исследовали способность врастания костных тканей в пористые имплантаты из сферических и губчатых порошков титана. Авторы отмечают, что к поверхности губчатых порошков титана костные ткани прирастают плотно, а от гладкой поверхности сферической частицы легко отслаиваются. Но, как известно, пористые поверхности могут провоцировать усталостные разрушения.

Усталостное разрушение является одной из важных проблем при эксплуатации имплантатов. Установленные на длительный срок имплантаты в процессе движения тела испытывают многократные циклические нагрузки, а нахождение металлических материалов длительное время в жидкой солевой среде провоцирует зарождение усталостных трещин на поверхности.

На рис. 1 приведены пример усталостного разрушения ортопедических имплантатов и микроструктура поверхности изломов. Исследование изломов показало, что независимо от материала имплантата причиной разрушения является усталость материала. Стрелками показаны бороздки, характерные для усталостного разрушения.

Таким образом, к состоянию поверхности имплантата возникают взаимоисключающие требования: с одной стороны, развитая шероховатость и пористость, с другой - стойкость к зарождению усталостных трещин, которые при изгибных нагрузках обычно возникают на шероховатых поверхостях. Решением проблемы может стать получение специальной формы шероховатости, минимизирующей концентрацию напряжений на поверхности.

В настоящей работе методом математического моделирования проведена оценка концентрации напряжений для различных форм шероховатости, а затем предложен путь для получения оптимальной структуры поверхности.

\section{МОДЕЛИРОВАНИЕ И РАСЧЕТ МЕХАНИЧЕСКИХ НАПРЯЖЕНИЙ}

Для определения влияния различной формы шероховатости поверхности на распределение и на величину напряжений при изгибе использовали математическое моделирование методом конечных элементов с помощью пакета ANSYS. Приложенная нагрузка на образцы $(50 \mathrm{H})$, как и прочие условия, были одинаковыми.

На рис. 2 представлено распределение напряжений $\sigma_{x}$, оказывающих наибольшее влияние на зарождение усталостных трещин. Анализ результатов моделирования показал, что наименьшее значение концентрации напряжений создают грибовидные наросты на поверхности (рис. 2, г). Следовательно, оптимальную форму 


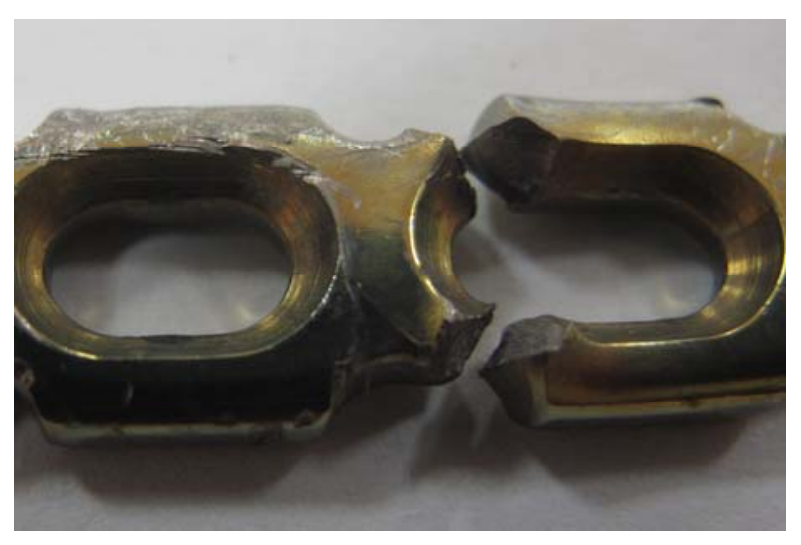

$a$

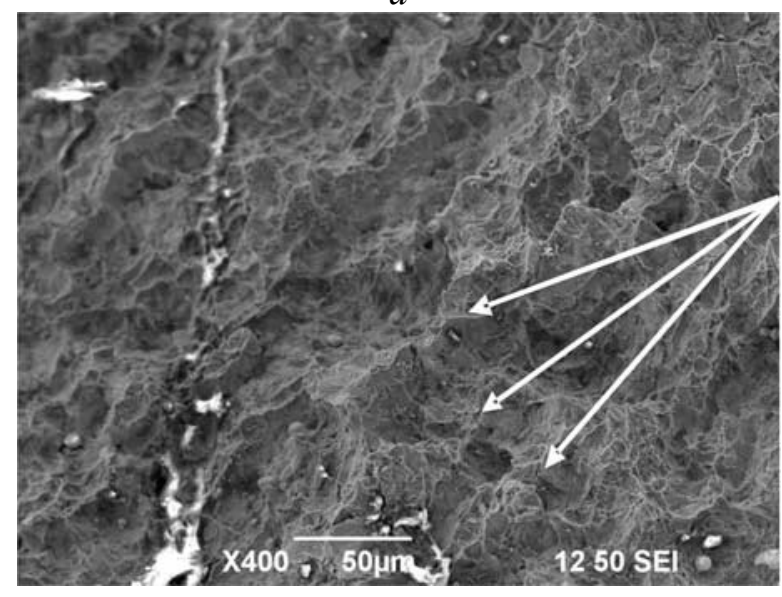

B

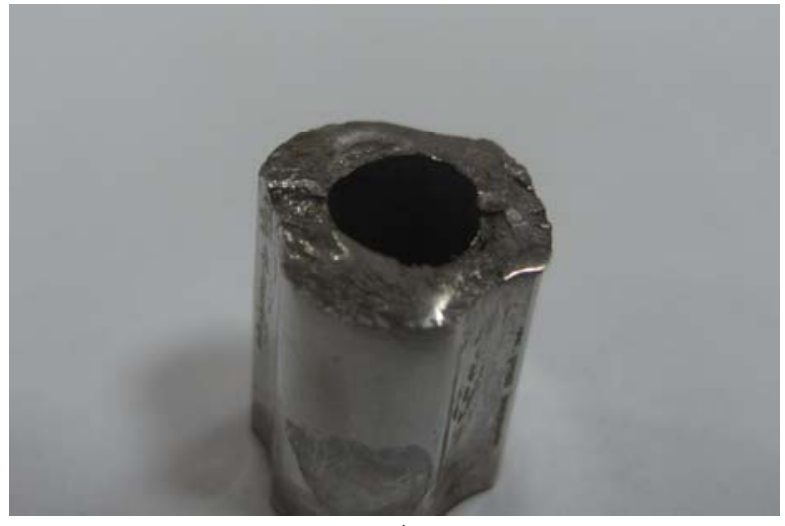

$\sigma$

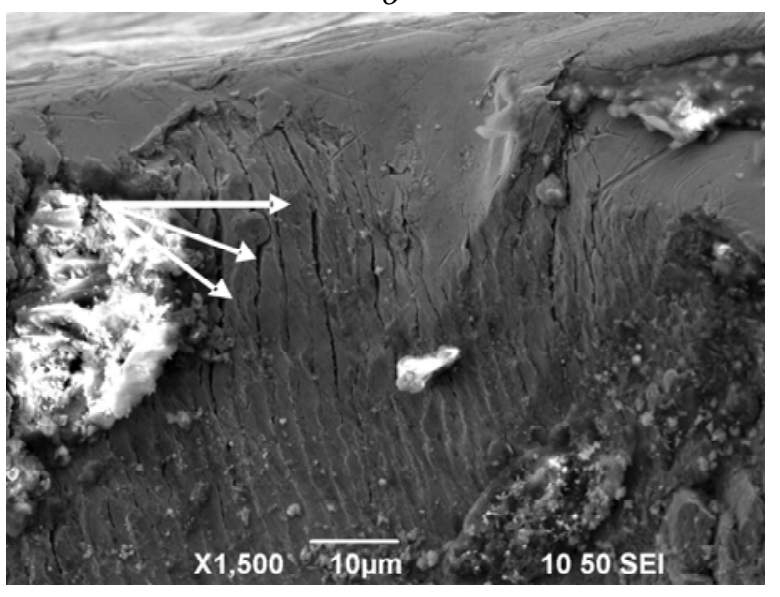

2

Рис. 1. Усталостное разрушение медицинских имплантатов из титанового сплава Ti-6Al-4V (BT6) (a); нержавеющей стали 316L (03X17H14M3) (б) и микроструктура изломов $(b, 2)$ соответственно

шероховатости могут придать частицы, соединенные перешейком с основанием имплантата. В то же время этот вид поверхности должен обладать достаточной прочностью на срез, что определяется прочностью материала, количеством наростов на единицу площади поверхности и диаметром перешейков.

$$
\tau=\frac{P}{n \cdot F} \leq[\tau]
$$

где $P$ - нагрузка, $\mathrm{H} ; n$ - количество перемычек; $F$ - площадь поперечного сечения перешейка, мм², в предположении, что его форма в сечении круглая, $F=\pi d^{2} / 4$.

В работе [4] показано, что достаточная прочность соединения имплантата с костной тканью соответствует напряжению среза $27 \mathrm{H} / \mathrm{mm}^{2}$. Учитывая среднее значение предела прочности технически чистого титана $353 \mathrm{MПа,} \mathrm{получим} \mathrm{допустимое}$ напряжение на срез перешейков: $[\tau] \leq 0,6, \sigma_{\mathrm{B}}=212$ МПа. Отсюда относительная площадь, занятая перешейками, должна быть не менее 12,8 \%.

Подобного вида структуру можно получить путем диффузионного спекания порошков с гладкой поверхностью основания имплантата. При этом необходимо получить определенный размер и форму пор, перешейков и других элементов структуры. Регулировать эти параметры можно подбором температуры и времени спекания. Однако следует учитывать, что чрезмерное увеличение температуры и времени выдержки приводит к огрублению микроструктуры основания и, как следствие, к снижению усталостной прочности [1]. Известно, что улучшить результат диффузионной сварки можно за счет предварительного растворения в титане 

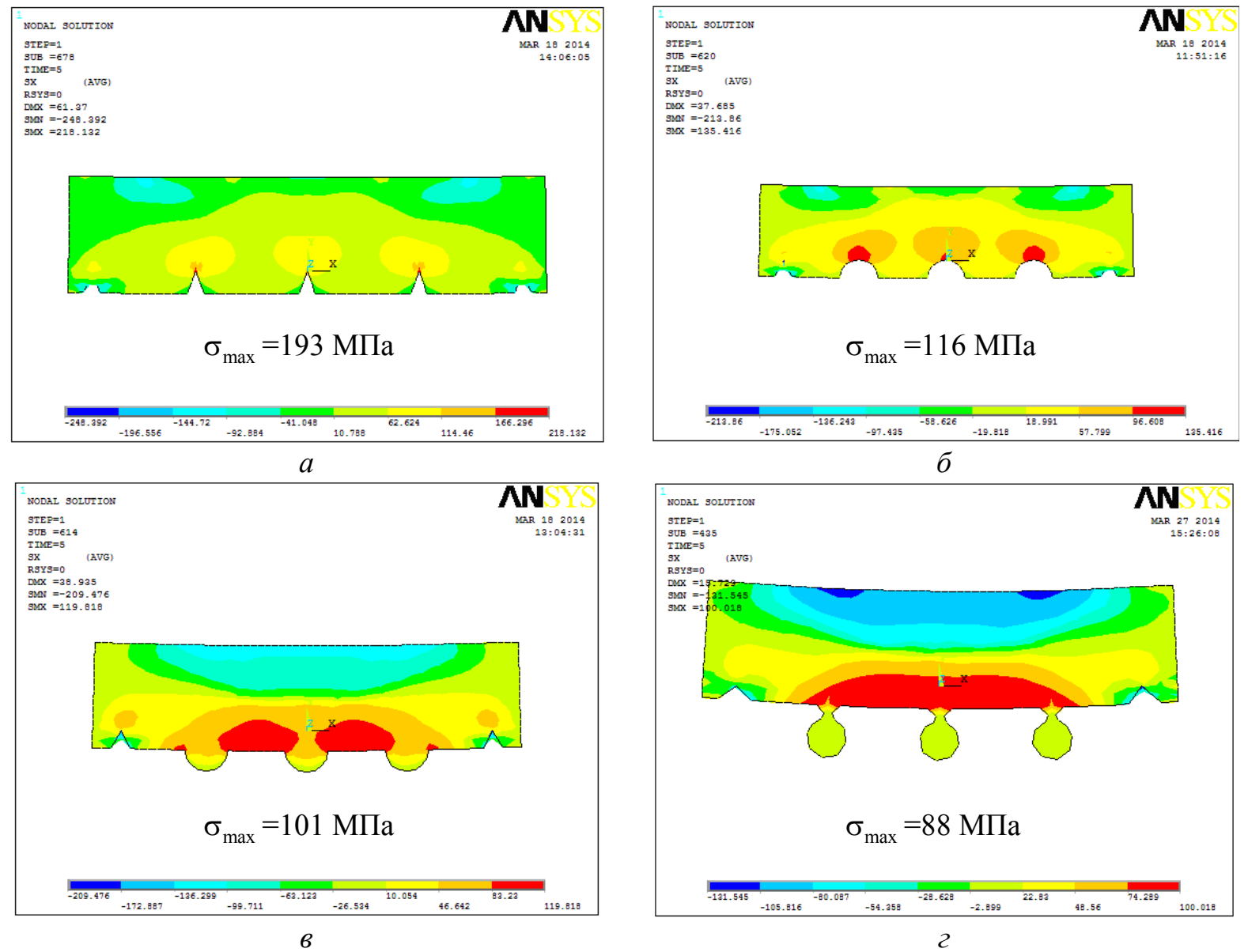

Рис. 2. Напряженное состояние образцов с различной шероховатостью поверхности (внизу дана цветовая шкала величин эквивалентных напряжений, МПа)

некоторого количества водорода [3]. С этой целью проведены эксперименты по диффузионному спеканию титановых порошков, в том числе содержащих водород, с образцами из титанового сплава.

\section{МАТЕРИАЛ И МЕТОДИКА ИССЛЕДОВАНИЙ}

Эксперименты по диффузионной сварке основы из титанового сплава ВТ6 с порошком титана ВТ1-0 и Ті-Н проводились с помощью установки для изотермической вакуумной формовки и отжига «ФерриВатт», величина вакуума $10^{-5}$ мм рт. ст. Сварка проводилась при температурах 700, 800, 900 и $950{ }^{\circ} \mathrm{C}$, время выдержки при постоянном давлении составляло 2 и 4 ч, охлаждение с печью. Образцы для подложки из сплава ВТ6 имели форму пластины с размерами $17 \times 17 \times 3$ мм. Размер частиц порошка технически чистого титана (Ti) и титана с растворенным в нем водородом (Тi-H) составлял 576 и 6 мкм соответственно. Порошок насыпался на поверхность отполированного и обезжиренного образца, а сверху придавливался плоским грузом массой 1,5 кг.

Микроструктуру в вертикальном сечении образца, запрессованного в полимер, исследовали с помощью оптического микроскопа OLYMPUS GX51. С целью повышения контраста изображения шлифы не подвергали травлению. Относительную площадь перешейков оценивали по их относительной ширине в плоскости шлифа, что при достаточной статистике измерений вполне адекватно. 


\section{РЕЗУЛЬТАТЫ ЭКСПЕРИМЕНТОВ И ОБСУЖДЕНИЕ}

При температуре $700{ }^{\circ} \mathrm{C}$ независимо от времени выдержки и присутствия водорода диффузионное соединение не образуется. Повышение температуры до $800{ }^{\circ} \mathrm{C}$ и выше привело к появлению перешейков между частицами и подложкой (рис. 3), а также между самими частицами.

Можно выделить следующие особенности. Порошок Ті (см. рис. 3, a) при $900{ }^{\circ} \mathrm{C}$ (2 часа) сваривается таким образом, что в зоне контактных перешейков остаются острые краевые углы с довольно острыми вершинами. Подобная конфигурация вызывает высокую концентрацию напряжений в вершинах углов и приводит к снижению прочности соединений. Повышение времени спекания (4 часа) и температуры до $950{ }^{\circ} \mathrm{C}$ (рис. 3, б) несколько увеличивает радиусы закругления при вершинах краевых углов, но радикально конфигурацию не меняет.

Результат существенно меняется для порошка, содержащего водород (см. рис. 3, 6, 2). Краевые углы и радиусы закругления при вершинах увеличиваются. Часто встречаются тупые краевые углы и широкие перешейки. Особенно это заметно при условиях $950{ }^{\circ} \mathrm{C}, 4$ часа. Частицы, свариваясь между собой, образуют сплошную губку.

Режим спекания и наличие водорода влияют на относительную площадь (ширину) перешейков (таблица). Повышение температуры, как и времени спекания, увеличивает относительную ширину перешейков. Сравнивая одни и те же режимы, можно видеть, что присутствие водорода заметно влияет на эту величину.
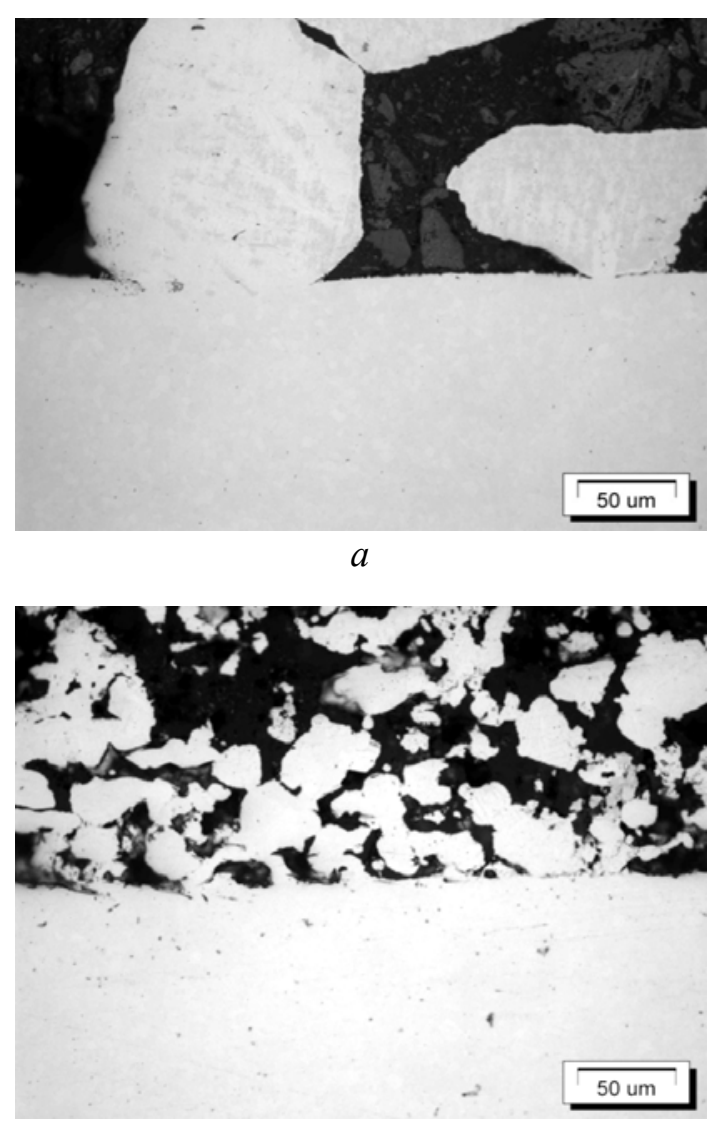

B
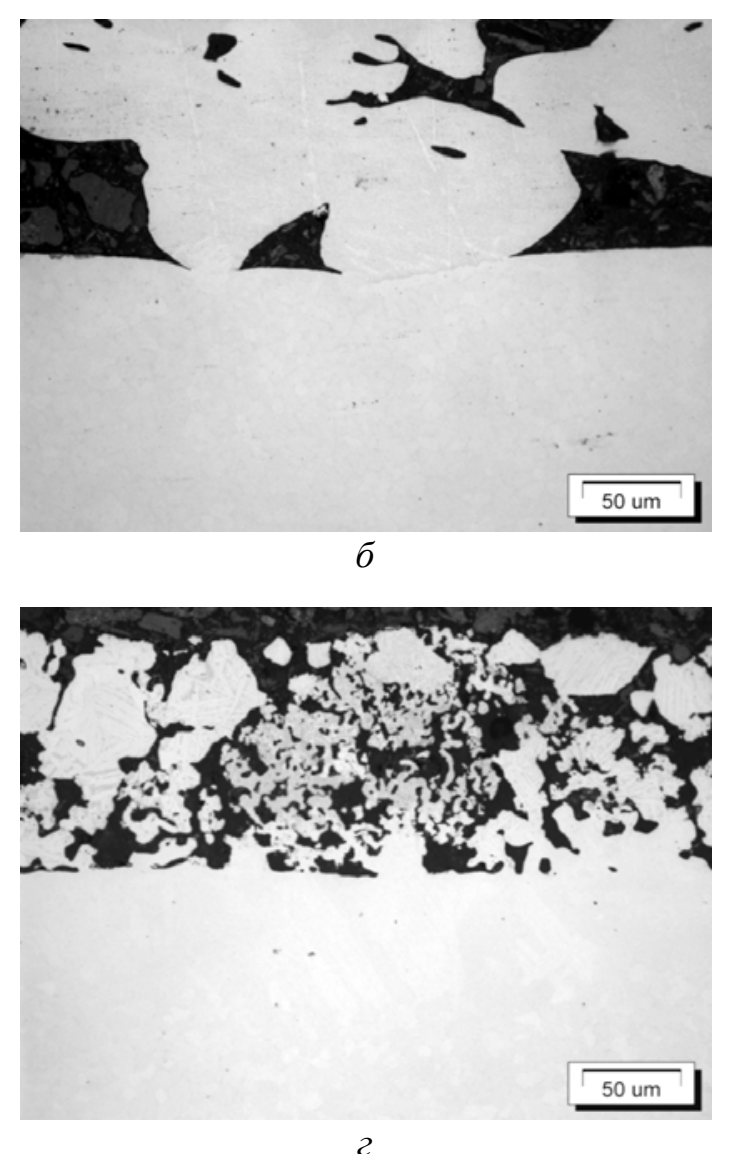

Рис. 3. Диффузионная связь порошка Ті $(a, 6)$ и Ті-Н $(b, 2)$ с основой из сплава ВТ6: $a-900{ }^{\circ} \mathrm{C}, 2$ ч; $\sigma-950{ }^{\circ} \mathrm{C}, 4$ ч; $в-900{ }^{\circ} \mathrm{C}, 2$ ч; $2-950{ }^{\circ} \mathrm{C}, 4$ ч 
Влияние режима спекания на относительную ширину перешейков

\begin{tabular}{|c|c|c|c|}
\hline Порошок & $t, \mathrm{ч}$ & $T,{ }^{\circ} \mathrm{C}$ & $\begin{array}{c}\text { Относительная ширина } \\
\text { перешейков }\end{array}$ \\
\hline \multirow{5}{*}{$\mathrm{Ti}$} & \multirow{2}{*}{2} & 800 & 0,016 \\
\hline & & 900 & 0,072 \\
\hline & \multirow{3}{*}{4} & 800 & 0,008 \\
\hline & & 900 & 0,024 \\
\hline & & 950 & 0,044 \\
\hline \multirow{6}{*}{ Ti-H } & \multirow{3}{*}{2} & 800 & 0,057 \\
\hline & & 900 & 0,045 \\
\hline & & 950 & 0,209 \\
\hline & \multirow{3}{*}{4} & 800 & 0,018 \\
\hline & & 900 & 0,118 \\
\hline & & 950 & 0,227 \\
\hline
\end{tabular}

Возвращаясь к условию прочности связи с костной тканью, можно отметить, что порошок титана без водорода не обеспечивает необходимой относительной площади перешейков, для порошка Тi-Н условие прочности выполняется при режимах $950{ }^{\circ} \mathrm{C}$, 2 часа и 4 часа.

Формирование качественного диффузионного соединения облегчается в результате усиленной водородом адгезии [3]. Причины усиления адгезии пары титантитан не ясны в достаточной степени. Ясно, однако, что они не связаны с образованием гидридов, так как компактводородные процессы эффективны лишь при таких высоких температурах (800-950 $\left.{ }^{\circ} \mathrm{C}\right)$, когда гидриды в титановых сплавах не образуются. Возможно, благоприятное действие водорода связано с тем, что он способствует формированию более рыхлой оксидной пленки на поверхности титана и его сплавов, а также более легкому и быстрому ее растворению. Еще одна причина может быть связана с обусловленным водородом облегчением и усилением межатомного взаимодействия атомов при контакте титана с титаном при повышенных температурах [3].

Заметим, однако, что при низких температурах водород уменьшает когезивную прочность металлов, это является одной из причин водородной хрупкости, особенно при знакопеременных нагрузках. Вакуумный отжиг удаляет водород из титана, но насколько полно и какова оптимальная концентрация водорода - эти и другие вопросы выходят за рамки данной работы и будут рассмотрены в дальнейшем.

\section{Выводы}

Наименьшее значение концентрации напряжений на поверхности основания имплантата создают грибовидные наросты, соединяющие губчатый слой с основанием и получаемые с помощью диффузионного спекания порошка.

Насыщение порошка водородом способствует получению необходимой структуры пористого слоя при температурах $900-950{ }^{\circ} \mathrm{C}$ и времени выдержки 2-4 часа.

\section{СПИСОК ЛИТЕРАТУРЫ}

1. Братухин А.Т., Колачев Б.А., Садков В.В., Талалаев В.Д. Технология производства титановых самолетных конструкций. - М.: Машиностроение, 1995. - 448 с. 
2. Забелин С.Ф., Дорожков А.А. Совершенствование технологии получения металлических имплантантов биомедицинского назначения // Ученые записки ЗабГГПУ. Серия: Физика, Математика, Техника, Технология. - 2011. - № 3. - С. 85-92.

3. Ильин А.А., Колачев Б.А., Носов В.К., Мамнов А.М. Водородная технология титановых сплавов. М.: МИСИС, 2002. - 392 с.

4. Ильющенко А.Ф., Савич В.В. Возможности и перспективы использования технологий порошковой металлургии, модифицирования поверхности и нанесения защитных покрытий в изделиях медицинской техники. 50 лет порошковой металлургии Беларуси. История, достижения, перспективы. - Минск, 2010. - С. 542-577.

5. Ночовная Н.А., Черемушникова Е.В., Анташев В.Г. Металлические материалы для эндопротезирования / под общ. ред. академика РАН Е.Н. Каблова. - М.: ВИАМ, 2014. - 72 с.

6. Савич В.В., Сарока Д.И., Киселев М.Г., Макаренко М.В. Модификация поверхности титановых имплантатов и ее влияние на их физико-химические и биомеханические параметры в биологических средах. - Минск: Беларус. Навука, 2012. - 244 с.

7. Hudak R., Penhaker M., Majernik J. Biomedical Engineering - Technical Applications in Medicine. Rijeka, Croatia: InTech, 2012. - 432 p.

\section{APPLICATION OF HYDROGENATED TITANIUM POWDERS TO OBTAIN A SURGICAL IMPLANTS WITH POROUS COATING BY VACUUM SINTERING}

\section{V.V. Astanin, E.Z. Kayumova, V.V. Nikitin, A.I. Farhetdinov (Ufa, Russia)}

The success of metallic materials in orthopedics and traumatology depends on the nature of the interaction between the implant and the living bone tissue. Rough surface of medical implants is known to have a beneficial effect on osseointegration processes. The best results are observed for surfaces with the controlled porosity. However, surface roughness and porosity have a negative effect on the fatigue strength under cyclic loading. Investigations of failure implants provided by a practitioner doctor of orthopedics and traumatology showed fatigue character in all cases of fracture. Irregularities on the implants surface play a role of stress concentrators and induce the formation of fatigue cracks. Therefore, it is necessary to obtain the optimal surface structure in order to resolve the contradictions between the demands of osseointegration and fatigue strength. This paper assesses the stress concentration for various forms of surface roughness by the method of mathematical modeling and determines the surface structure of titanium implants less predisposed to the incipience of fatigue cracks. As a result the method for producing such a surface consisting in a diffusion vacuum sintering powders with a smooth substrate surface of the implant is proposed. Effect of temperature and sintering time on the obtaining of the porous surface is studied detail. Moreover, the positive effect of the hydrogen contained in the powder on the sintering process is experimentally obtained. In this work, basing on the literature about bond strength of the implant with the bone tissue, calculation of the required relative area occupied by isthmus between powder particles and the substrate of the implant is performed. Time-temperature mode, conducing to the formation of regulated surface structure is determined.

Key words: implant, fatigue of material, finite element method, surface roughness, diffusion sintering. 